\title{
Risk Management In College Fraternities: Guidance From Two Faculty Advisors
}

Stuart Rosenberg, Ph.D., Monmouth University, USA

Joseph Mosca, Ed.D., Monmouth University, USA

\begin{abstract}
Students who become members of fraternities and sororities avail themselves of significant opportunities that enrich their college life. Faculty advisors play an important role in assisting fraternities and sororities in shaping students' leadership, scholastic, and personal development. Given the risks such as alcohol use and hazing that continue to be associated with Greek life, faculty advisors also need to be actively involved in enforcing various policies to ensure student safety. In this paper, the authors review some of the problems that cause a liability risk to Greek life and they offer examples from their own experience as faculty advisors to two fraternities to help manage the risk.
\end{abstract}

Keywords: College Fraternities; Risk Management; Faculty Advisor

\section{THE PROBLEM}

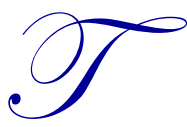
here was an avalanche of bad publicity for college fraternities in the twelve months between March 2014 and March 2015. Unfortunately, problems that have long been associated with fraternitiesalcohol abuse, hazing, and sexual violence-have attracted so much attention on college campuses across America that there has been an outcry for change, including the banning of fraternities altogether. These problems of course can take place on any college campus-large and small, public and private.

- March 2014: A public university in the Middle Atlantic States suspended a fraternity for six years after one of its pledges committed suicide by jumping from the roof of a Marriott hotel. The student had photos on his phone of a blindfolded pledge with a gun to his head. The student also had text messages on his phone explaining that pledges had to choose between penetrating themselves with a sex toy or snorting cocaine (Pace, 2014).

- April 2014: A public university in the South disbanded the chapter of a fraternity after an investigation showed that the fraternity had circulated an email from its leadership calling women "rapebait" (Pace, 2014).

- May 2014: Fourteen members of a fraternity at a private college in the Midwest were arrested in connection with a hazing incident earlier in the school year that resulted in one of the pledges losing a testicle. In the incident, pledges were blindfolded, ordered to strip and lie on the floor, where they were then whipped with towels. The student, who required surgery, defended the fraternity when he referred his injury as a "freak accident" (Hensley, 2014).

- September 2014: University police at a public university in the Midwest conducted an investigation of a fraternity when several women were found with red and black X's on their hands after they had been hospitalized with memory lapses from intoxication at a fraternity party (Valenti, 2014). The university subsequently revoked the fraternity's charter.

- September 2014: A public university in the Southwest suspended the chapter of a national fraternity after the fraternity displayed a banner reading "No means yes, and yes means anal" (New, 2014). That same month, the university also suspended another fraternity after a freshman pledge was found dead of acute alcohol intoxication at an off-campus party (Pace, 2014).

- September 2014: A private university in the Northeast announced that its fraternities would be required to become coeducational following complaints from students and faculty that fraternities encourage sexism and mistreatment of women (New, 2014). Five months later, the university was being sued by a 
national fraternity. As reported in The New York Times (Santora, 2015, p. A24), a spokesman for the fraternity's alumni organization stated, "Discrimination is abhorrent in whatever form it may exist. [The president's] pursuit of selective discrimination is an egregious example of political correctness gone wrong, and does a disservice to the high ideals upon which [the university] was founded."

- September 2014: A public university in the South suspended all fraternity activity after a student's fatal plunge from a bridge (New, 2014).

- October 2014: A public university in the South suspended a fraternity indefinitely from its campus after a student who was pledging into the fraternity broke into the local zoo to steal two Chilean flamingos, which later died. The student, who was suspended by the university, was arrested on grand larceny charges (Pace, 2014).

- November 2014: A public university in the South suspended all fraternity and sorority activities indefinitely after an 18-year old student collapsed and died at a fraternity house (Connolly, 2014). Two fraternity members were subsequently charged with hazing-related misdemeanors. According to author and hazing expert, Hank Nuwer, at least one student has died every year in a hazing-related incident since 1970 (Nuwer, 2014).

- November 2014: A private university in the Middle Atlantic States suspended a fraternity and banned all open fraternity parties after a 16-year old reported being raped at one such party (Connolly, 2014).

- December 2014: A private university in the Northeast banned a fraternity from its campus, suspended two students and expelled another following an investigation of a hazing incident. The university refused to disclose the details (Moran, 2014).

- February 2015: An Ivy League school banned the chapter of a national fraternity from campus in connection with a violation involving a "presentation" at an initiation ceremony during 2014 (McDonald \& Lauerman, 2015). This fraternity has previously been dubbed America's deadliest frat after nine people died between 2006 and 2014 in pledging-related activities (Flanagan, 2014).

These cases only represent a sampling of the types of incidents that have occurred in college fraternities. Clearly, schools across the country have become more sensitized about student safety following a May 2014 press release issued by the Department of Education that listed 55 higher education institutions with open Title IX sexual violence investigations.

Two incidents in particular in the last few months generated national headlines and added fuel to the fire concerning fraternity behavior. The first was an article published in Rolling Stone in November 2014. The article shed light on (a) cases where reports might be fabricated or false; and (b) cases that simply do not get reported. The Rolling Stone article described a brutal gang rape of a woman named "Jackie" during a party at a University of Virginia fraternity house. The article depicted the tacit allowance of the behavior by Jackie's friends, who seemed more concerned about the stigma of their own social standing. In the wake of the story, the university president ordered a full investigation. Because of the sensitive nature of Jackie's story, Rolling Stone decided to honor her request not to contact the man who she claimed orchestrated the attack on her nor any of the men whom she claimed participated in the attack for fear of retaliation against her (Erdely, 2014). In the weeks following the article, new information surfaced that questioned the evidence reported in the article and Rolling Stone issued an apology.

The second incident took place in March 2015. The University of Oklahoma severed ties to one of the nation's largest fraternities and after videos surfaced that showed a group of white fraternity members dressed in tuxedos riding a bus and singing a song laden with anti-black slurs. (This is the same fraternity involved in the February 2015 incident mentioned above.) University president David L. Boren said, "These people have acted in a way that is absolutely reprehensible and disgraceful. I don't have words in my vocabulary to adequately describe how I feel about people who would use those words in that way, and chant in that way" (Fernandez \& Perez-Pena, p. A11). Two fraternity members were dismissed from the university within a week of the incident, yet First Amendment supporters complained that the expulsions were unjust. 


\section{NO EASY ANSWER}

Given the perceived connection between students involved in Greek life and sexual assault and binge drinking (i.e., consuming five or more drinks during a single drinking occasion for men and four or more drinks for women), some campuses have taken aggressive steps to curb these dangerous behaviors. At Dartmouth College, where two-thirds of eligible students are members of fraternities and sororities, the administration announced extensive changes in January 2015. The changes included banning hard liquor, forbidding the pledge process at fraternities and sororities, and requiring the entire student body to undergo a four-year sexual violence prevention program (Rocheleau, 2015). Even more aggressively, some schools have abolished fraternities and sororities completely. The institutions that have done this are mostly small private liberal arts colleges on the East coast, including Colby, Bowdoin, Middlebury, and Williams. Such a move is likely to be unfeasible at larger schools, however, where fraternities have deep pockets as well as deep roots. As examples, Ohio State University has 38 fraternities and 24 sororities, while at the University of Alabama, more than 7,000 undergraduates are members of the Greek system (New, 2014).

Moreover, some opponents of the idea argue that instead of reducing instances of sexual assault and heavy drinking, barring fraternities and sororities could actually exacerbate these problems. There's always the risk that if a school were to force fraternities off campus, the behavior would return in underground fraternities that could not be regulated by colleges.

An example of one such underground fraternity existed at a private university on the East coast, whose notorious behavior operated with impunity for over a decade until April 2014 (Ryan, 2014). Two members of this underground fraternity, which was an "open secret" on campus, allegedly ran down a student with a car and then beat him while yelling anti-gay slurs until he fell unconscious. The student was hospitalized with a severe concussion and a spinal strain. Fraternities and sororities at this university had moved off campus in the 1990s after the campus had become "dry." Sanctioned fraternities started popping up in surrounding neighborhoods, and the underground fraternity followed suit. A few days before the April 2014 incident, 70+ pages of emails from the underground fraternity were leaked to the university community containing rape jokes, references to the physical assault of women, and threats of further assaults. In the leaked emails one of the men implicated in the April 2014 assault implicated himself in an earlier assault that had occurred on campus. The underground fraternity's members felt that they had achieved an element of power due to the inability of the university administration to rein them in. Although students and alumni at the university by then had begun to pressure the administration to act more decisively, there was concern within the university community that the sort of culture found in the underground fraternity might have already become too much a part of the university culture to bring about positive change (Ryan, 2014).

Another school that also attracted national attention for an underground fraternity is the aforementioned private university in the Northeast that announced it was requiring coed fraternities in September 2014. The secret fraternity in question continued to operate outside the university's oversight after it had been stripped from official fraternity status for refusing to admit female pledges. The underground fraternity had earned the nickname "The Rape Factory" and it was the center of a lawsuit filed by a woman who alleged to have been raped in its common room (Ryan, 2014).

In May 2014, a private college in the Northeast banned its students from joining any fraternity or sorority, including underground fraternities, which it had allowed to organize as long as their activities remained off campus. This followed a federal complaint by a female student who accused the college of mishandling her sexual assault case. The complaint resulted in the college being added to the list of schools under investigation by the U.S. Department of Education related to the violation of the gender equity law, for the sexually hostile climate created by underground fraternities (Kingkade, 2014). 
Kevin Kruger, the president of the National Association of Student Personnel Administrators (NASPA), summed up the issues facing fraternities and sororities in the following statement:

The really negative things are really so awful. But I think for many campuses, trying to work within the Greek system is better than not having it at all. When fraternities and sororities are done well, they really are extraordinary leadership opportunities. But when they are done poorly, it's truly horrific. (New, 2014, para. 20)

\section{LITERATURE REVIEW}

Research has shown that the highest proportion of heavy drinkers and individuals with diagnosable alcohol use disorders and multiple substance dependencies are in the age range encompassing over 90 percent of all enrolled college students, between the ages of 18 and 21 (Grant, 1997; O’Malley \& Johnston, 2002). The task force report of the National Institute on Alcohol Abuse and Alcoholism (2002) described the general acceptance and excessive use of alcohol on college campuses as a culture.

Various attempts have been made both in terms of public policy and interventions across college campuses to address the problem of heavy drinking by college students. The most widely used policy tool in the campaign against youth and young adult alcohol abuse has been higher minimum drinking ages. Following a downward trend in legal drinking ages beginning in 1971 when the voting age was lowered to 18 , alcohol abuse among the young increased significantly (Chaloupka \& Wechsler, 1996). As a result, the National Minimum Drinking Age Act was passed by Congress in 1984. Other legislative strategies have included stronger drunk driving policies targeting youths and young adults and increased taxation of alcoholic beverages that are passed on to consumers in the form of higher prices. While the former has helped to reduce student drinking, the latter has not, as drinking practices are price inelastic (Chaloupka \& Wechsler, 1996).

During the 1980s and 1990s, college administrators began in earnest to adopt intensive on-campus alcohol and drug abuse education and prevention programs (Dodge, 1991; Kunz, Irving, \& Black, 1993; Magner, 1988; Morritz, Seehafer, \& Maatz-Majestic, 1993). Despite the progress made as a result of actions taken by lawmakers and college administrators, within the general population of college students there continued to be two groups who demonstrate a higher risk of engaging in risky drinking and experiencing alcohol-related problems-college athletes and Greekletter social organization members (Turrisi, Mallett, Mastroleo, \& Larimer, 2006).

In a NASPA study by Wechsler, Kuh, \& Davenport (2009), it was found that 86 percent of fraternity house residents engaged in binge drinking as compared to 45 percent of non-fraternity men. Wechsler, Moeykens, Davenport, Castillo, \& Hansen (1995) identified some of the negative effects associated with this behavior as the secondhand consequences of alcohol use. Second-hand consequences affect those who are in close proximity to drinkers; examples include noise disruptive of sleep and study, property damages, interpersonal violence, and time spent taking care of others who are intoxicated.

Research has linked heavy drinking in college fraternities with rape. Foubert, Newberry, \& Tatum (2007) found that while the majority of fraternity members do not commit rape, they are three times more likely to than non-members. Kalof (2000) conducted a study that measured social coercion, alcohol or drug related nonconsensual sex, and physical coercion. Social coercion represents unwanted sexual intercourse forced through nonviolent means, such as threats to end the relationship or lies. In alcohol-or-drug related nonconsensual sex, the victim is unable to consent because of being under the influence of alcohol or drugs. Physical coercion represents forced intercourse through physical force or threat of physical force. Acquaintance rapes (or date rapes) account for most of the rapes that are reported. However, because of the personal connection to the perpetrator, the victim might not classify what has happened as rape. The actual number of rapes is therefore likely to be underreported.

With such findings about Greek life, it is important to look at the individual characteristics that have an impact on individuals' decisions to join fraternities and sororities. Research has shown that students with positive attitudes toward alcohol use tend to gravitate toward environments and social groups that foster high-risk drinking (Borsari \& Carey, 1999; Cashin, Presley, \& Meilman, 1998; Klein, 1992). The self-selection process into fraternities is higher 
for men who tend to place a higher priority on socialization, peer relationships, and have a higher need for acceptance (Borsari \& Carey, 1999). Since most of the alcohol consumed by Greek social members takes place in fraternity houses (Arnold \& Kuh, 1992), observing heavy drinking by peers is common. Inflated normative perceptions such as quantity, frequency, and acceptability of drinking among Greek members have been shown to perpetuate heavy drinking (Baer, Stacy, \& Larimer, 1991; Goodwin, 1989; Larimer, Turner, Mallet, \& Geisner, 2004; Sher, Bartholow, \& Nanda, 2001).

There are of course other, more positive, considerations that attract students to Greek life. Sirhal (2000) reminds us that Greek letter fraternities and sororities beginning with Phi Beta Kappa in 1776 at the College of William and Mary are quintessentially American. They deliver the benefits of a more intimate setting in which to share ideas, build lasting friendships, and acquire support from a set of peers in a world that is, for most students, their first experience of life lived separately from their families. According to the 1997 survey by the National Panhellenic Conference and North American Interfraternity Conference, Greek alumni are the building blocks of social capital. They are people who go on to volunteer and help to propel communities, while contributing more generously to their alma mater than do non-Greeks (as cited in Sirhal, 2000).

Nonetheless, given the persistence of the relationship between drinking and Greek life, many colleges and universities have implemented policies that aim to reduce problem drinking and manage liability in the Greek system. There exists a growing body of literature on policy interventions to reduce drinking and related consequences within that system. Research has shown that members will drink less at fraternity parties if given incentive to do so (Fournier, Earhart, Glindemann, \& Geller, 2004). Dornier, Fauquier, Field, \& Budden (2010) and others have pointed to the importance of mandatory alcohol education programs. Some research, however, suggests that intervention policies have actually increased risky drinking behavior. One study evaluated a program that was implemented by the University of Washington to replace kegs with a "bring your own booze" policy at Greek social functions. The authors found that one year after implementation, fraternity and sorority members were drinking less frequently, but consuming more alcohol per occasion (Kilmer, Larimer, Parks, Dimeff, \& Marlatt (1999). The truth of the matter is that some of the interventions that have proved successful in the general college student population have simply not shown the same success in fraternities and sororities. In particular, those interventions aimed to correct inaccurate and inflated peer norms of drinking behavior and approval of heavy drinking have faced barriers from fraternities and sororities (Barnett, Far, Mauss, \& Miller, 1996; Carter \& Kahneiler, 2000).

\section{DISCUSSION}

The authors are faculty advisors for the chapters of two different national fraternities at Monmouth University. We firmly believe that Greek life offers significant benefits to students and we both have observed the personal growth among the brothers in our respective fraternities during their college years and beyond. The reason for this growth is due not only to the ideals of the fraternities, but also to the norms that have been established as well as practical faculty oversight.

A major component of faculty oversight consists of discussing the risks of drinking, hazing, and sexual assault that have beset college fraternities and then developing strategies to minimize the liability. Strategies for managing the risk of drinking that have met with success include safe ride programs and the promotion of non-alcoholic events. Strategies for managing the risk of hazing that have met with success include the monitoring of initiation activities by the faculty advisor and the assurance of transparency in fraternity rituals. Strategies for managing the risk of sexual assault include emphasizing to the brothers that they always know who their guests are, ensuring that they are prudent with the use of technology (i.e., social media), and intervention by the faculty advisor whenever it is deemed necessary.

\section{RECOMMENDATIONS}

There are a number of recommendations that can help other faculty advisors to guide the fraternities on their campuses. Of paramount importance are the following: 


\section{Stay Involved in the Oversight of the Rush Process}

The faculty advisor needs to be familiar with all activities related to the handling of pledges. This requires open lines of communication between the advisor and all members of the fraternity. The communication must be treated with candor and seriousness.

\section{Maintain A Presence at Social Functions}

The faculty advisor needs to be made aware of what the function is and where it is being held. The advisor does not necessarily need to attend every function, but the fraternity should know that the advisor might show up. This "open invitation" to the advisor for social functions is appropriate given the relationship between the advisor and the fraternity and it has proven to help minimize liability.

\section{Advise Freshmen and Sophomores Against Living Off-Campus}

Having two years to mature in the environment that university residence halls provide is significant. Off-campus living arrangements offer less structure and, consequently, more risk. This recommendation is particularly important for students involved in Greek life at our university, which does not have fraternity houses.

\section{Assign Pledges to Be Designated Drivers at Functions}

This is a reasonable practice. Pledges are generally freshmen and sophomores and below the legal drinking age. In the absence of a university sponsored ride program, it is helpful for students to know how things are going to be handled before an event begins

\section{Schedule Regular Meetings with the Fraternity}

These meetings are independent of chapter meetings. As an example, weekly luncheons with the fraternity have proven to be an excellent forum to discuss any issues that either the brothers or the faculty advisor might wish to raise. Moreover, the weekly luncheons are a good way to build camaraderie.

\section{Ensure That Academic Performance and Service Are Always the Highest Priority}

One of the real benefits of being in a fraternity is that there is a dedicated faculty advisor to assist students. The advisor can provide motivation as well as access to resources in order to help create high academic achievement. In addition, being a part of a close-knit group fosters support that helps to strengthen academic performance. Engagement in service activities is a cornerstone of Greek life, and the benefit of having such a requirement is that it exposes fraternity members to the importance of citizenship.

\section{Establish Rituals to Build Trust and Earn Respect}

One of the authors has developed rituals that have achieved significant success in obtaining the trust and respect of the chapter members. An example is "the candle," where midway through each semester the advisor joins the fraternity in a dark room and everyone is seated in a circle. The candle is passed from brother to brother, and when each person gets the candle he speaks out about anything that is on his mind. When the lights go on, everyone in the room has a deeper sense of pride in their brotherhood. Another example is "the paddle," where each year the new pledges create a paddle for the advisor. The advisor hangs the paddle of each pledge class on the wall of his office; it is a symbol of the bonding that takes place each year between the pledges and between the pledges and the faculty advisor.

\section{CONCLUSION}

It has been our experience that by following these practices as faculty advisors, the fraternity members that we have had the privilege of working with over the years have succeeded both on an academic level and on a social level. 
Their lives have been enriched as a result of their being involved in Greek life. They have been able to have fun while at the same time be safe.

We have developed many of our methods by trial and error or by consulting with other advisors. We feel that it is important for universities to offer training for new faculty advisors to fraternities and sororities, since this would help to propagate best practices.

\section{AUTHOR BIOGRAPHIES}

Dr. Stuart Rosenberg, Associate Professor of Management at the Leon Hess Business School, earned his doctorate at Fordham University. His research has covered many areas, and he is particularly interested in the intersection of management and culture. His work has been published in a number of journals, including Education + Training, Case Research Journal, The CASE Journal, Journal of Business \& Economic Studies, Journal of Applied Case Research, International Journal of Management and Information Systems, and Journal of Business \& Economics Research. He is also the author of the book Rock and Roll and the American Landscape: The Birth of an Industry and the Expansion of the Popular Culture. srosenbe@monmouth.edu.

Dr. Joseph Mosca, Associate Professor of Management at the Leon Hess Business School, earned his doctorate at New York University. Dr. Mosca specializes in Human Resource Management, Human Relations, and active teaching methods, and is the recipient of seven teaching awards and three distinguished paper awards. His current research interests focus on developing hybrid courses, employee behavior, and jobs in the 21st century. mosca@monmouth.edu.

\section{REFERENCES}

Arnold, J. C., \& Kuh, G. D. (1992). Brotherhood and the Bottle: A Cultural Analysis of the Role of Alcohol in Fraternities. Bloomington, IN: Center for the Study of the College Fraternity.

Baer, J. S., Stacey, A., \& Larimer, M. (1991). Biases in the perception of drinking norms among college students. Journal of Studies on Alcohol, 52, 580-586.

Barnett, L. A., Far, J. M., Mauss, A. L., \& Miller, J. A. (1996). Changing perceptions of peer norms as a drinking reduction program for college students. Journal of Alcohol and Drug Education, 41, 39-62.

Borsari, B. E., \& Carey, K. B. (1999). Understanding fraternity drinking: Five recurring themes in the literature, $1980-1998$. Journal of American College Health, 48, 30-37.

Carter, C. A., \& Kahnweiler, W. M. (2000). The efficacy of the social norms approach to substance abuse prevention applied to fraternity men. Journal of American College Health, 49, 66-71.

Cashin, J. R., Presley, C. A., \& Meilman, P. W. (1998). Alcohol use in the Greek system: Follow the leader? Journal of Studies on Alcohol, 59, 63-70.

Chaloupka, F. J., \& Wechsler, H. (1996). Binge drinking in college: The impact of price, availability, and alcohol control prices. Contemporary Economic Policy, 14, 112- 124.

Connolly, M. (2014). Another major university has banned frats after a series of disturbing incidents. Retrieved from http://mic.com/articles/104310/another-university-had-stopped-greek-life-after-a-disturbing-incident.

Dodge, S. (1991). The use of beer kegs banned by some colleges and fraternities. The Chronicle of Higher Education, $24-27$.

Dornier, L. J., Fauquier, K. J., Field, A. R., \& Budden, M. C. (2010). Understanding and confronting alcohol-induced risky behavior among college students. Contemporary Issues in Education Research, 3(6), 45-54.

Erdely, S.R. (2014). A rape on campus: A brutal assault and struggle for justice at UVa. Retrieved from http://www.rollingstone.com/culture/features/a-rape-on-campus-20141119.

Fernandez, M., \& Perez-Pena, R. (2015). Fraternity is closed over video with slurs. The New York Times, March 9, p. A11.

Flanagan, C. (2014). What Sigma Alpha Epsilon's pledging ban won't fix. Retrieved from http://www.washingtonpost.com/opinions/what-sigma-alpha-epsilons-pledging-ban-wont-fix/2014/03/14/58b777c8aac5-11e3-98f6-8e3c562f9996_story.html.

Foubert, J. D., Newberry, J. T., \& Tatum, J. L. (2007). Behavior differences seven months later: Effects of a rape prevention program. NASPA Journal, 44(4), 728-749.

Fournier, A. K., Earhart, I. J., Glindemann, K. E., \& Geller, E. S. (2004). Intervening to decrease alcohol abuse at university parties: Differential reinforcement of intoxication level. Behavior Modification, 28, 167-181.

Goodwin, L. (1989). Explaining alcohol consumption and related experiences among fraternity and sorority males. Journal of College Student Development, 30, 448-458. 
Grant, B. F. (1997). Prevalence and correlates of alcohol use and DSM-IV alcohol dependence in the United States. Results of the national longitudinal alcohol epidemiologic survey. Journal of Studies on Alcohol, 58, 464-473.

Hensley, N. (2014) 14 charged in Ohio's Wilmington College hazing during fraternity ritual. Retrieved from http://www.nydailynews.com/news/crime/14-charged-fraternity-hazing-cost-man-testicle-article-1.1811704.

Kalof, L. (2000). Vulnerability to sexual coercion among college women: A longitudinal study. Gender Studies (Fall), 47-58.

Kilmer, J. R., Larimer, M. E., Parks, G. A., Dimeff, L. A., \& Marlatt, G. A. (1999). Liability management or risk management? Evaluation of a Greek system alcohol policy. Psychology of Addictive Behaviors, 13, 269-278.

Kingkade, T. (2014). Amherst College bans students from joining fraternities. Retrieved from http://www.huffingtonpost.com/2014/05/06/amherst-college-fraternities-ban_n_5275705.html.

Klein, H. (1992). College students' attitudes toward the use of alcohol beverages. Journal of Alcohol and Drug Education, 37, $35-52$.

Kunz, M. L., Irving, W. M., \& Black, D. R. (1993). Health services at large public institutions: Funding, utilization, and staffing. Journal of American College Health, 42, 3-14.

Larimer, M. E., Turner, A. P., Mallett, K. A., \& Geisner, I. M. (2004). Predicting drinking behavior and alcohol-related problems among fraternity and sorority members: Examining the role of descriptive and injunctive norms. Psychology of Addictive Behaviors, 18, 203-212.

Magner, D. K. (1988). Alcohol-related problems have not decreased on most college campuses, survey indicates. Chronicle of Higher Education, A35.

McDonald, M., \& Lauerman, J. (2015). Yale bans SAE fraternity citing sexual policy violation. Retrieved from http://www.bloomberg.com/news/articles/2015-02-13/yale-bans-sae-fraternity-for-violating-sexual-misconduct-policy.

Moran, D. (2014). Quinnipiac University bans fraternity, suspends students for hazing. Retrieved from http://touch.courant.com/\#section/-1/article/p2p-82424121/.

Morritz, T., Seehafer, R. W., \& Maatz-Majestic, E. (1993). A student competition to develop an innovative alcohol education strategy. Journal of American College Health, 41, 283-286.

National Institutes of Health. (2002). Task Force of the National Advisory Council on Alcohol Abuse and Alcoholism. Retrieved from http://www.collegedrinkingprevention.gov/media/taskforcereport.pdf.

New, J. (2014). Should colleges ban fraternities and sororities? Retrieved from https://www.insidehighered.com/news/2014/09/30/should-colleges-ban-fraternities-and-sororities.

Nuwer, H. (2014). Hank Nuwer's list of deaths by hazing. Retrieved from http://www.hanknuwer.com/hazingdeaths.html.

O’Malley, P. M., \& Johnston, L. D. (2002). Epidemiology of alcohol and other drug use among American college students. Journal of Studies on Alcohol, 63(Supp. 14), 23-39.

Pace, M. (2014). College fraternities under fire for hazing, offensive behavior. Retrieved from http://www.washingtontimes.com/news/2014/oct/12/colleges-fraternities-under-fire-for-hazing-deaths/?page=all.

Rocheleau, M. (2015). Dartmouth bans hard alcohol, forbids Greek life pledging: Moves target binge drinking, sex assaults. Retrieved from http://www.bostonglobe.com/metro/2015/01/29/dartmouth-college-ban-hard-alcohol-forbid-greek-lifepledging-among-slew-policy-changes/WCxS4OHSLK5hZ5Z7u5E8iN/story.html.

Ryan, E. G. (2014). The story behind American University's rapey, violent 'secret' frat. Retrieved from http://jezebel.com/thestory-behind-american-universitys-rapey-violent-se-1566309032.

Santora, M. (2015). Fraternity sues Wesleyan over order to admit women. The New York Times, February 19, p. A24.

Sher, K. J., Bartholow, B. D., \& Nanda, S. (2001). Short- and long-term effects of fraternity and sorority membership on heavy drinking: A social norms perspective. Psychology of Addictive Behaviors, 15, 42-51.

Sirhal, M. (2000). Fraternities on the rocks. Policy Review (February-March), 55-67.

Turrisi, R., Mallett, K., Mastroleo, N., \& Larimer, M. (2006). Heavy drinking in college students: Who is at risk and what is being done about it? The Journal of General Psychology, 133(4), 401-420.

U.S. Department of Education (2014). U.S. Department of Education releases list of higher education institutions with open Title IX sexual violence investigations. Retrieved from http://www.ed.gov/news/press-releases/us-department-educationreleases-list-higher-education-institutions-open-title-i.

Valenti, J. (2014). Frat brothers rape 300\% more; one in five women is sexually assaulted on campus: Should we ban frats? Retrieved from http://www.theguardian.com/commentisfree/2014/sep/24/rape-sexual-assault-ban-frats.

Wechsler, H., Moeykens, B., Davenport, A., Castillo, S., \& Hansen, J. The adverse impact of heavy episodic drinking on other college students. Journal of Studies on Alcohol, 56, 628-635.

Wechsler, H., Kuh, G., \& Davenport, A. E. (2009). Fraternities, sororities and binge drinking: Results from a national study of American colleges. NASPA Journal, 46(3), 395-416. 